\title{
Competitive Inhibition of Bile Acid Synthesis by Endogenous Cholestanol and Sitosterol in Sitosterolemia with Xanthomatosis

\author{
Effect on Cholesterol $7 \alpha$-Hydroxylase
}

\author{
S. Shefer, G. Salen, L. Nguyen, A. K. Batta, V. Packin, G. S. Tint, and S. Hauser \\ Department of Medicine and the Sammy Davis, Jr. National Liver Institute, University of Medicine and Dentistry of New Jersey-New \\ Jersey Medical School, Newark, New Jersey 07103; and Veterans Administration Medical Center, East Orange, New Jersey 07019
}

\begin{abstract}
The $7 \alpha$-hydroxylation of two cholesterol analogues, sitosterol and cholestanol, and their effect on the $7 \alpha$-hydroxylation of cholesterol were measured in rat and human hepatic microsomes. In untreated rat liver microsomes, the $7 \alpha$-hydroxylation of cholesterol was higher than that of cholestanol (1.4fold) and sitosterol (30-fold). After removal of endogenous sterols from the microsomes by acetone treatment, the $7 \alpha$-hydroxylation of cholesterol was similar to that of cholestanol and only fourfold higher than that of sitosterol. Cholestanol and sitosterol competitively inhibited cholesterol $7 \alpha$-hydroxylase in both rat and human liver microsomes, with cholestanol the more potent inhibitor. Patients with sitosterolemia with xanthomatosis, who have elevated microsomal cholestanol and sitosterol, showed reduced cholesterol $7 \alpha$-hydroxylase activity relative to the activity in control subjects (13.9 and 14.7 vs. 20.3 $\pm 0.9 \mathrm{pmol} / \mathrm{nmol} \mathbf{P}-450$ per $\mathrm{min}, \boldsymbol{P}<0.01)$. Enzyme activity in these patients was $40 \%$ higher when measured in microsomes from which competing sterols had been removed. Ileal bypass surgery in one sitosterolemic patient decreased plasma cholestanol and sitosterol concentrations and resulted in a $\mathbf{3 0 \%}$ increase in hepatic microsomal cholesterol $7 \alpha$-hydroxylase activity. Cholesterol $7 \alpha$-hydroxylase appears to have a specific apolar binding site for the side chain of cholesterol and is affected by the presence of cholestanol and sitosterol in the microsomal substrate pool. Reduced bile acid synthesis in sitosterolemia with xanthomatosis may be related to the inhibition of cholesterol $7 \alpha$-hydroxylase activity by endogenous cholesterol analogues.
\end{abstract}

\section{Introduction}

According to current information, the main pathway for the degradation of cholesterol ${ }^{1}$ in mammals is its conversion into

Address reprint requests to Dr. Sarah Shefer, Department of Medicine, MSB H-534, University of Medicine and Dentistry of New Jersey-New Jersey Medical School, 185 Orange Avenue, Newark, NJ 07103-2757.

Received for publication 1 February 1988 and in revised form 15 July 1988.

1. The following systematic names are given to compounds referred to by trivial names: cholesterol, 5 -cholesten-3 $\beta$-ol; cholestanol, $5 \alpha$-cholestan-3 $\beta$-ol; sitosterol, $24 \alpha$-ethyl-5-cholesten-3 $\beta$-ol; sitostanol, $24 \alpha$ ethyl-5 $\alpha$-cholestan-3 $\beta$-ol; campesterol, $24 \alpha$-methyl-5-cholesten-3 $\beta$-ol; campestanol, $24 \alpha$-methyl-5 $\alpha$-cholestan-3 $\beta$-ol; stigmasterol, $24 \alpha$-ethyl5,22-cholestadien-3 $\beta$-ol; $7 \alpha$-hydroxycholesterol, 5-cholestene- $3 \beta$,

J. Clin. Invest.

(c) The American Society for Clinical Investigation, Inc.

$0021-9738 / 88 / 12 / 1833 / 07 \$ 2.00$

Volume 82, December 1988, 1833-1839 bile acids. The major rate-controlling step in bile acid synthesis is the $7 \alpha$-hydroxylation of cholesterol catalyzed by the microsomal enzyme, cholesterol $7 \alpha$-hydroxylase (EC 1.14.13.17). Although newly synthesized cholesterol is the preferred substrate for this enzyme, other hepatic microsomal cholesterol pools can be used for the transformation to bile acids. About $300-500 \mathrm{mg}$ of bile acids are formed daily in humans under normal conditions but, when stimulated, bile acid synthesis can be increased two to threefold. Up to $1 \mathrm{~g}$ of cholesterol thus can be $7 \alpha$-hydroxylated and transformed into bile acids daily via this pathway.

For the past few years, bile acid synthesis has been measured by assessing the activity of hepatic microsomal cholesterol $7 \alpha$-hydroxylase. The most commonly used assay is the isotope incorporation method, in which radioactive cholesterol is incorporated into the microsomal cholesterol pool and the formation of radioactive $7 \alpha$-hydroxycholesterol is determined (1). Results obtained by this method may be confounded by the endogenous pool of microsomal sterols, especially when the size and composition of this pool vary. Various cholesterol analogues accompany cholesterol in virtually every mammalian tissue and may affect $7 \alpha$-hydroxycholesterol formation $(2,3)$. Significant amounts of cholestanol are present in the liver of patients with the rare, inherited lipid storage disease cerebrotendinous xanthomatosis (4), and large amounts of plant sterols, in addition to cholestanol, are deposited in the liver of patients with sitosterolemia with xanthomatosis (5).

This study describes the $7 \alpha$-hydroxylation of sitosterol and cholestanol and their effect on the $7 \alpha$-hydroxylation of cholesterol in human and rat liver microsomal preparations in vitro. Enzyme activities were measured in the absence of endogenous microsomal sterols by a previously validated method that involves the extraction of endogenous sterols by acetone $(1,6)$, and compared with those obtained in untreated microsomes. The effect of the endogenous sterol substrate pool on cholesterol $7 \alpha$-hydroxylase activity in patients with sitosterolemia with xanthomatosis was also evaluated.

\section{Methods}

Human subjects. Six control subjects (aged 16-54) and two sisters with sitosterolemia with xanthomatosis (aged 24 and 26) were included in the study. Of the six control specimens, four were obtained from the "Liver Tissue Procurement and Distribution System" (National Insti-

$7 \alpha$-diol; $7 \beta$-hydroxycholesterol, 5-cholestene-3 $\beta, 7 \beta$-diol; $7 \alpha$-hydroxycholestanol, $5 \alpha$-cholestane- $3 \beta, 7 \alpha$-diol; $7 \beta$-hydroxycholestanol, $5 \alpha$ cholestane-3 $\beta, 7 \beta$-diol; $7 \alpha$-hydroxysitosterol, $24 \alpha$-ethyl-5-cholestene-3 $\beta, 7 \alpha$-diol; $7 \beta$-hydroxysitosterol, $24 \alpha$-ethyl-5-cholestene-3 $\beta$ 7 $\beta$-diol. 
tutes of Health contract NO1-DK-62274, University of Minnesota Hospital, Minneapolis, MN) and two were liver biopsies obtained for diagnostic histologic evaluation from normolipidemic subjects with normal liver morphology and function tests. Complete clinical descriptions of the sitosterolemic subjects have been published previously (7). Liver biopsies were obtained from two untreated sitosterolemic patients and repeated in one patient 9 mo after ileal bypass surgery. The experimental protocol was approved by the Human Study Committees of the Veterans Administration Medical Center, East Orange, $\mathrm{NJ}$ and the University of Medicine and Dentistry of New Jersey Medical School. Informed consent was obtained from each subject.

Animals. Male Sprague-Dawley rats (Taconic Farms, Germantown, NY) weighing 100-150 $\mathrm{g}$ were fed ad lib. ground rat chow (Ralston-Purina Co., St. Louis, MO) containing 2.5\% cholestyramine for $7 \mathrm{~d}$. The rats were decapitated and their livers were removed immediately and chilled on ice. The animal protocol was approved by the Animal Studies Committee at the University of Medicine and Dentistry of New Jersey.

Purification and labeling of substrates. $\left[4-{ }^{14} \mathrm{C}\right]$ Cholesterol (New England Nuclear, Boston, MA) was diluted with unlabeled cholesterol (Supelco, Inc., Bellefonte, PA) to a specific activity of $5 \times 10^{6}$ $\mathrm{dpm} / \mu \mathrm{mol}$ and purified by column chromatography on a $\mathrm{AgNO}_{3}$-silicic acid column (2). The purified radioactive cholesterol contained $<0.06 \% 7 \alpha$-hydroxycholesterol, $0.01 \% 7 \beta$-hydroxycholesterol, and $0.04 \%$ cholestanol as determined by thin-layer chromatography (TLC) ${ }^{2}$ on a $\mathrm{AgNO}_{3}$-impregnated silica gel $\mathrm{G}$ plate (8) and by scintillation counting (Intertechnique SL 4000 , Fairfield, NJ). [3 $\left.\alpha-{ }^{3} \mathrm{H}\right]-$ Cholestanol (specific activity $1.4 \times 10^{7} \mathrm{dpm} / \mu \mathrm{mol}$ ) was prepared by reduction of $3 \mathrm{mg} 5 \alpha$-cholestan-3-one with $1 \mathrm{mg} \mathrm{NaBT}{ }_{4}$ in $0.5 \mathrm{ml}$ methanol for $2 \mathrm{~h}$. The product was isolated by preparative TLC on silica gel $\mathrm{G}$ plates (Brinkmann Instruments, Westbury, NY) using chloroform/acetone (99:1 vol/vol). The major spot, $R_{\mathrm{f}} 0.5$, was eluted with chloroform $/$ methanol $(90: 10 \mathrm{vol} / \mathrm{vol})$ and was found to be $>99 \%$ pure by TLC and zonal radioactivity scanning. It was further purified by chromatography on a $\mathrm{AgNO}_{3}$-silicic acid column (2). The purified product contained $<0.04 \%$ cholesterol, $0.04 \% 7 \alpha$-hydroxycholestanol and $0.01 \% 7 \beta$-hydroxycholestanol as seen by TLC-scintillation counting. $\left[4-{ }^{14} \mathrm{C}\right]$ Sitosterol (Amersham Corp., Arlington Heights, IL) was diluted with unlabeled sitosterol (Supelco, Inc.) to a specific activity of $3.6 \times 10^{6} \mathrm{dpm} / \mu \mathrm{mol}$ and was purified from its oxidation products by column chromatography as described for cholesterol (2). It was further purified by HPLC on a liquid chromatograph (ALC 201; Waters Associates, Milford, MA) with a refractive index detector (model $401)$ and a radial-pack $\mu$ Bondapak $C_{18}$ reversed-phase column $(10 \mu \mathrm{m}$ particle size). The mobile phase consisted of methanol/chloroform/ water $(90: 2: 10 \mathrm{vol} / \mathrm{vol} / \mathrm{vol}$ ), at a flow rate of $2 \mathrm{ml} / \mathrm{min}$ (operating pressure $2,000 \mathrm{psi}$ ). The pure compound was eluted at $24.8 \mathrm{ml}$ (Table I) and contained $<0.05 \% 7 \alpha$-hydroxysitosterol, $0.02 \% 7 \beta$-hydroxysitosterol (as determined by TLC-scintillation counting), $0.03 \%$ campesterol, and $0.02 \%$ stigmasterol (as determined by HPLC-scintillation counting).

Enzymes, cofactors, and reagents. NADPH and DTT were purchased from Calbiochem-Behring Corp. (La Jolla, CA); EDTA, Triton $\mathrm{X}-100, \mathrm{NaF}$, deoxycholate (DCA), and dilauroylphosphatidylcholine (DLPC) from Sigma Chemical Co. (St. Louis, MO); $\left[{ }^{3} \mathrm{H}\right]$ acetic anhydride $(50 \mathrm{mCi} / \mathrm{mmol})$ from New England Nuclear. Cholestyramine was a gift from Bristol-Myers Co. (Evansville, IN). 7-Ketocholesterol, $7 \alpha-$, and $7 \beta$-hydroxycholesterol were synthesized as described by Fieser et al. (9). 7-Ketocholestanol, $7 \alpha$-, and $7 \beta$-hydroxycholestanol were synthesized as described by Wintersteiner and Moore (10). 7-Ketositosterol, $7 \alpha$-, and $7 \beta$-hydroxysitosterol were synthesized by oxidation of sitosterol acetate with tertiary butyl perbenzoate as described by Starka (11). NADPH-cytochrome P-450 reductase was purified from

2. Abbreviations used in this paper: DLPC, dilauroylphosphatidylcholine; GLC, gas-liquid chromatography; Na-DCA, deoxycholic acid, sodium salt; TLC, thin-layer chromatography; TMSi, trimethylsilyl.
Table I. Capillary GLC and HPLC Characteristics of Neutral Sterols and their $5 \alpha$-Stanols

\begin{tabular}{lcc}
\hline \multicolumn{1}{c}{ Compound } & $\begin{array}{c}\text { GLC* } \\
\text { (RRT) }\end{array}$ & $\begin{array}{c}\text { HPLC } \\
\text { (Retention volume) }\end{array}$ \\
\hline & & $m l$ \\
Cholesterol & 1.86 & 18.8 \\
$5 \alpha$-Cholestanol & 1.71 & 20.2 \\
Sitosterol & 2.86 & 24.8 \\
5 $\alpha$-Sitostanol & 2.72 & 26.6 \\
Campesterol & 2.36 & 22.0 \\
5 $\alpha$-Campestanol & 2.24 & 23.7 \\
Stigmasterol & 2.46 & 22.5 \\
Avenosterol & 3.46 &
\end{tabular}

* Fused silica capillary column $(0.32 \mathrm{~mm} \times 26 \mathrm{~m})$ coated with a $0.21-\mu \mathrm{m}$ film of CP Wax $52 \mathrm{CB}$ Column temperature, $210^{\circ} \mathrm{C} ; \mathrm{He}$ flow, $1.0 \mathrm{ml} / \mathrm{min}$. RRT, Retention times of TMSi ethers relative to $5 \alpha$-cholestane (12 min). $\mathrm{C}_{18} \mu$ Bondapak reversed-phase column (10- $\mu \mathrm{m}$ particle size); mobile phase, methanol/chloroform/water $(90: 2: 10 \mathrm{vol} / \mathrm{vol} / \mathrm{vol})$ at $2.0 \mathrm{ml} / \mathrm{min}$.

rat liver microsomes according to the method of Yasukochi and Masters (12).

Sterol determination in hepatic microsomes. Known aliquots of untreated or acetone-treated microsomal suspensions were refluxed for $3 \mathrm{~h}$ with $25 \% \mathrm{KOH}$ in $95 \%$ ethanol (wt/vol). Sterols were extracted with $n$-hexane (6) and analyzed by capillary GLC (13) as trimethylsilyl (TMSi) ether derivatives on a gas chromatograph (model 5890; Hewlett-Packard Co., Palo Alto, CA) equipped with a flame ionization detector and fitted with an open tubular fused silica column $(0.32 \mathrm{~mm}$ $\times 26 \mathrm{~m}$ ) that was internally coated with a $0.21-\mu \mathrm{m}$ film of CP Wax 52CB (Chrompack, Inc., Bridgewater, NJ). The following operating conditions were used: injection temperature $275^{\circ} \mathrm{C}$; column temperature (isothermal) $210^{\circ} \mathrm{C}$, flame ionization detector temperature $295^{\circ} \mathrm{C}$, helium carrier gas flow, $1.0 \mathrm{ml} / \mathrm{min}$, and split ratio, $10: 1$.

Preparation and assay of cholesterol $7 \alpha$-hydroxylase. Rat livers were excised at $\sim 10$ a.m. to minimize diurnal variations in bile acid synthesis, and all subsequent operations were carried out at $4^{\circ} \mathrm{C}$. Microsomes were isolated and washed as described previously (1). The final pellet was suspended in a buffer $(0.1 \mathrm{M}$ potassium phosphate buffer, $20 \%$ glycerol, $1 \mathrm{mM}$ EDTA, $5 \mathrm{mM}$ DTT, and $50 \mathrm{mM} \mathrm{NaF}, \mathrm{pH}$ 7.4) at a protein concentration, as determined by Lowry et al. (14), of $\sim 30 \mathrm{mg}$ protein $/ \mathrm{ml}$ and stored at $-80^{\circ} \mathrm{C}$ until assayed. To remove endogenous sterols, $1 \mathrm{ml}$ of the microsomal suspension was added dropwise, with stirring, to $40 \mathrm{ml}$ acetone at $-10^{\circ} \mathrm{C}$. When the suspension had settled, the precipitate was collected by centrifugation at 1,000 $\mathrm{g}$ for $5 \mathrm{~min}$, washed, dried, ground, and stored as described previously (6). Before use, an aliquot of a known weight of the acetone powder (also referred to as acetone-treated microsomes) was homogenized in the above buffer. The cytochrome P-450 content of the untreated and acetone-treated microsomes was determined from the $\mathrm{CO}$ difference spectrum between 450 and $490 \mathrm{~nm}$ of the reduced sample using the extinction coefficient of $91 \mathrm{mM}^{-1}(15)$. These acetone-treated microsomal preparations contained $0.2-0.7 \mathrm{nmol} P-450$ and $<0.4 \mathrm{nmol}$ sterols/mg protein. Acetone treatment of the microsomes removed $90 \%$ of the phospholipids as assayed by the method of Chen et al. (16) and $50 \%$ of the NADPH-cytochrome P-450 reductase activity as assayed by the method of Yasukochi and Masters (12).

In standard incubations with untreated microsomes, aliquots (0.1-0.5 nmol P-450) were preincubated for $2 \mathrm{~min}$ at $37^{\circ} \mathrm{C}$ in a final volume of $0.5 \mathrm{ml}$ buffer $(100 \mathrm{mM}$ potassium phosphate, $0.1 \mathrm{mM}$ EDTA, and $1 \mathrm{mM} \mathrm{DTT}, \mathrm{pH} 7.4)$ containing $100 \mathrm{nmol}\left[4-{ }^{14} \mathrm{C}\right]-$ cholesterol solubilized with $0.15 \%$ Triton $\mathrm{X}-100$. The reaction was 
initiated by the addition of $0.6 \mu \mathrm{mol}$ NADPH. Incubations were carried out with shaking for $10 \mathrm{~min}$ at $37^{\circ} \mathrm{C}$, and were terminated by the addition of $15-20 \mathrm{vol}$ of methylene chloride/ethanol (5:1 vol/vol). Zero time controls were run with each experiment. The $7 \alpha$-hydroxycholesterol formed was extracted, acetylated with $\left[{ }^{3} \mathrm{H}\right]$ acetic anhydride, and separated by TLC on alumina G (Analtech, Inc., Newark, DE) as previously described (17). The acetylation step is needed to eliminate the underestimation of product formation that is due to the dilution of the labeled cholesterol by the endogenous cholesterol pool that also serves as substrate in the untreated microsomes. $\left[{ }^{3} \mathrm{H}\right]-$ Cholestanol and $\left[{ }^{14} \mathrm{C}\right]$ sitosterol were used as substrates only with rat liver microsomes and their respective $7 \alpha$-hydroxylated products were separated by TLC on silica gel G (Analtech, Inc.) without prior acetylation. The acetylation step was not necessary because endogenous cholestanol and sitosterol were not present in the rat liver microsomes. The TLC plates were developed with diethyl ether and the pertinent spots were visualized by spraying with $3.5 \%$ phosphomolybdic acid in isopropanol (6). The observed $R_{\mathrm{f}}$ values were: cholesterol, cholestanol, or sitosterol, $0.88 ; 7 \alpha$-hydroxycholesterol or $7 \alpha$-hydroxysitosterol, $0.40 ; 7 \beta$-hydroxycholesterol or $7 \beta$-hydroxysitosterol, $0.54 ; 7 \alpha$-hydroxycholestanol, 0.55 ; and $7 \beta$-hydroxycholestanol, 0.46 . The radioactivity of the pertinent spots was determined in a liquid scintillation counter.

When acetone-treated microsomes were used, the same assay conditions as described above were used except that $0.025 \mathrm{mg}$ DLPC, solubilized in $0.12 \mathrm{mM} \mathrm{Na-DCA}$, and 2 units of NADPH-cytochrome $\mathrm{P}-450$ reductase were added to the incubation mixture to replace membrane phospholipids and NADPH-cytochrome P-450 reductase lost in the preparation of acetone-treated microsomes. The $7 \alpha$-hydroxylated products were separated on silica gel $G$ plates without prior acetylation because of the absence of endogenous sterols. The cholesterol $7 \alpha$-hydroxylase activity in acetone-treated microsomes, assayed in this reconstituted system, was comparable to that of the untreated microsomes and has previously been shown to be similarly affected by bile acid malabsorption (cholestyramine treated) and by cholic acid feeding (6). We have noted that cytochrome P-420, which is devoid of enzyme activity, is formed in various amounts during the preparation of the acetone powder and if included in the calculations (e.g., when enzyme activity is expressed per milligram protein) it could lead to an underestimation of cholesterol $7 \alpha$-hydroxylase activity. All results are expressed in picomoles of product formed per nanomole microsomal cytochrome P-450 per minute.

Competitive inhibition assay. To determine the effect of cholestanol and sitosterol on cholesterol $7 \alpha$-hydroxylase activity in both rat and human acetone-treated microsomes, increasing amounts of unlabeled cholestanol $(5-300 \mu \mathrm{M})$ or sitosterol $(25-300 \mu \mathrm{M})$ were added to the assay systems together with the labeled cholesterol substrate. The concentrations of endogenous cholestanol and sitosterol in hepatic microsomes from patients with sitosterolemia and xanthomatosis were at least 5 and $25 \mu \mathrm{M}$, respectively, under the assay conditions used. When the type of inhibition was determined, varying concentrations of $\left[4-{ }^{14} \mathrm{C}\right]$ cholesterol were used with rat acetone-treated microsomes and its conversion to $7 \alpha$-hydroxycholesterol was measured in the presence of two different concentrations of unlabeled cholestanol or sitosterol ( 50 and $100 \mu \mathrm{M}$ for cholestanol, 100 and $200 \mu \mathrm{M}$ for sitosterol). Double reciprocal plots were used to determine the apparent $K_{\mathrm{m}}$ values in the presence and absence of inhibitory sterols.

Statistical significance of the data was determined by the unpaired $t$ test. In the comparison of sitosterolemic cholesterol $7 \alpha$-hydroxylase activities with control values, a normal distribution for the control data was assumed and a 0.01 confidence limit was calculated (18).

\section{Results}

$7 \alpha$-Hydroxylation of cholesterol, cholestanol, and sitosterol. The formation of $7 \alpha$-hydroxycholesterol $(2,19)$ and $7 \alpha$-hydroxycholestanol (2) by untreated hepatic microsomes have been reported previously and the same identification procedures of reaction products were used with the acetone-treated microsomes. To obtain enough material to carry out the identification of $7 \alpha$-hydroxysitosterol, the products from largescale (300-500-fold) incubation mixtures were combined and purified by TLC as described in Methods. The fraction corresponding to $7 \alpha$-hydroxysitosterol $\left(R_{\mathrm{f}}=0.4\right)$ was subjected to GLC analysis after trimethylsilylation, and was found to have an identical retention time to synthetic $7 \alpha$-hydroxysitosterol (3). Its specific radioactivity after dilution with authentic unlabeled $7 \alpha$-hydroxysitosterol $(1,100 \mathrm{dpm} / \mu \mathrm{mol})$ remained constant after crystallization from acetone/water and methanol/ water.

Optimal assay conditions for the $7 \alpha$-hydroxylation of cholestanol and sitosterol were determined and compared with those of cholesterol, using acetone-treated microsomal preparations that contained $<0.4 \mathrm{nmol}$ endogenous sterols per milligram protein (Fig. 1). The rates of formation of the $7 \alpha$-hydroxylated products were linear up to $1 \mu \mathrm{M}$ cytochrome $\mathrm{P}-450$ (Fig. $1 A$ ). Reaction rates were proportional to the incubation time during the first $20 \mathrm{~min}$ (Fig. $1 B$ ). The enzyme appeared to be saturated when the sterol concentration reached $200 \mu \mathrm{M}$ (Fig. $1 C$ ). The apparent $K_{\mathrm{m}}$ value of $46 \mu \mathrm{M}$ observed with acetone-treated microsomes was lower than the range of 80-225 $\mu \mathrm{M}$ reported for untreated microsomes (20-22) and closer to the value of $15 \mu \mathrm{M}$ observed with butanol/acetonetreated microsomes (23).

Substrate specificity. Fig. 2 shows sterol $7 \alpha$-hydroxylase activity with cholesterol, cholestanol, and sitosterol as substrates, determined in untreated (Fig. $2 A$ ) and acetone-treated (Fig. $2 B$ ) rat liver microsomal preparations. Cholesterol was the preferred substrate and the enzyme activity was 30 -fold
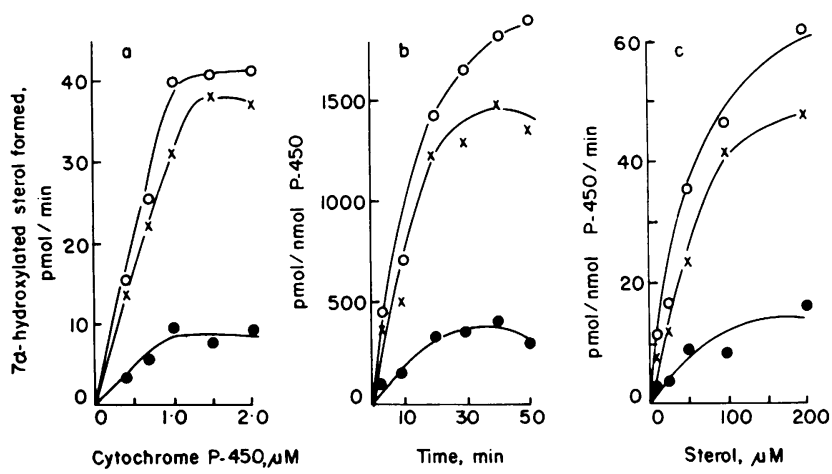

Figure 1. Effect of enzyme concentration, time, and substrate concentration on the $7 \alpha$-hydroxylation of labeled cholesterol (O), cholestanol $(x)$, and sitosterol $(\bullet)$. (A) Varying amounts of acetone-treated rat liver microsomes $(0.4 \mathrm{nmol} \mathrm{P}-450 / \mathrm{mg}$ protein $)$ were incubated at $37^{\circ} \mathrm{C}$ for $10 \mathrm{~min}$ in the presence of $200 \mu \mathrm{M}$ labeled detergent-solubilized sterol, $0.05 \mathrm{mg} / \mathrm{ml}$ DLPC solubilized in $0.12 \mathrm{mM} \mathrm{Na-DCA}, 2$ U NADPH-cytochrome P-450-reductase and $1.2 \mathrm{mM}$ NADPH. The $7 \alpha$-hydroxylated sterols formed were assayed by TLC and liquid scintillation counting. Each point is an average of two to three experiments, each performed in duplicate with correction for zero-time controls. The coefficient of variation of the assay was $<6 \%$. $(B)$ Assay conditions as described in $A$ were used, except incubation time was varied and two different $\mathrm{P}-450$ concentrations within the linear range were used for each sample. $(C)$ Assay conditions as described in $A$ were used, except the sterol concentration was varied and two different $\mathrm{P}-450$ concentrations within the linear range were used for each sample. 


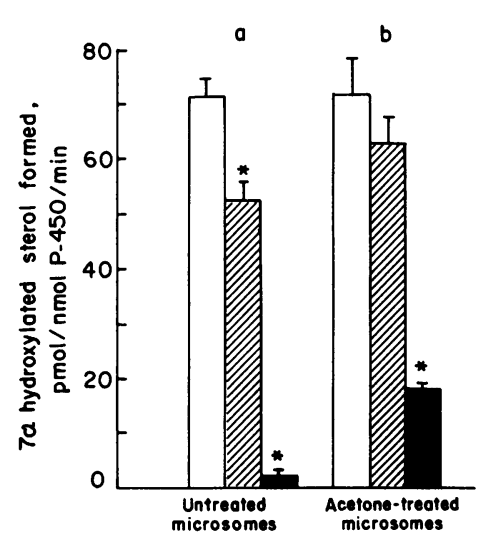

Figure 2. Substrate specificity of cholesterol $7 \alpha$-hydroxylase in untreated $(A)$ and $(B)$ acetone-treated rat liver microsomes. The open, hatched, and solid bars represent sterol $7 \alpha$-hydroxylase activity, assayed as described in Methods, with labeled cholesterol, cholestanol, and sitosterol as substrates, respectively. The data represent the means \pm SEM of six experiments, each done with duplicate samples. *, significantly different from enzyme activity with cholesterol as substrate. greater for cholesterol than for sitosterol and 1.4 times greater than for cholestanol $(P<0.0002)$ when measured in the untreated microsomes (Fig. $2 A$ ). When the incubation was carried out with the acetone-treated microsomes from which endogenous cholesterol had been removed (Fig. 2 B), cholesterol and cholestanol exhibited almost the same affinity toward the enzyme $(71.8 \pm 7.3$ and $63.0 \pm 4.8 \mathrm{pmol} / \mathrm{nmol} \mathrm{P}-450 / \mathrm{min}$, respectively; $P>0.05)$. The $7 \alpha$-hydroxylation of sitosterol, in the acetone-treated microsomes, was significantly lower $(18.4 \pm 0.8$ $\mathrm{pmol} / \mathrm{nmol} \mathrm{P}-450 / \mathrm{min}$ ) than that of cholesterol or cholestanol $(P<0.001)$, suggesting a lower affinity for the enzyme. However, it was increased eightfold relative to the value obtained with labeled sitosterol in the presence of endogenous cholesterol in untreated microsomes $(18.4 \pm 0.8$ from $2.4 \pm 0.6 \mathrm{pmol} /$ nmol P-450/min, $P<0.001$ ). Upon removal of endogenous cholesterol, the $7 \alpha$-hydroxylation of cholestanol was also increased to $63.0 \pm 4.8$ from $52.4 \pm 3.0 \mathrm{pmol} / \mathrm{nmol} \mathrm{P}-450 / \mathrm{min}$, though the difference was not statistically significant.

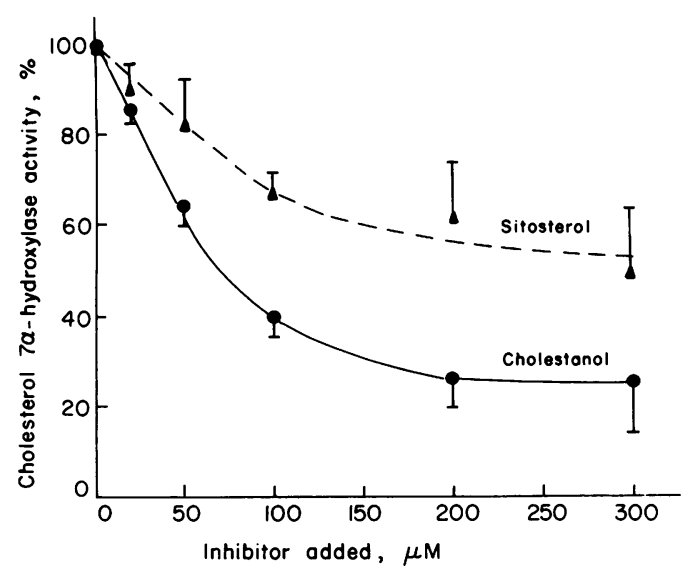

Figure 3. Inhibition of cholesterol $7 \alpha$-hydroxylase activity by cholestanol and sitosterol in acetone-treated rat liver microsomes. The enzyme activity was assayed with $\left[4-{ }^{14} \mathrm{C}\right]$ cholesterol as described in Methods in the presence of detergent-solubilized unlabeled cholestanol or sitosterol. Each point represents the mean \pm SEM of two to three experiments run in duplicate. $100 \%$ cholesterol $7 \alpha$-hydroxylase activity is $76.7 \pm 4.0 \mathrm{pmol} / \mathrm{nmol} \mathrm{P}-450 / \mathrm{min}$.

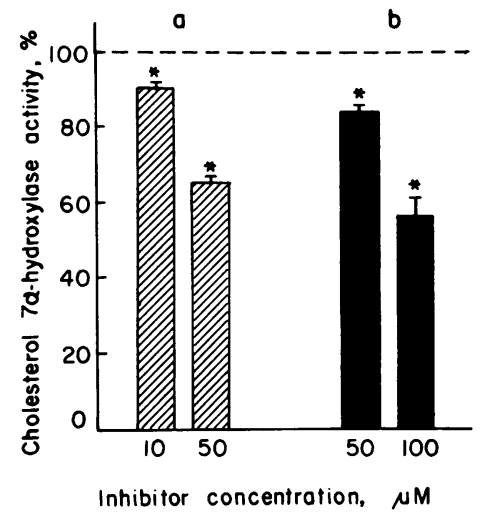

Figure 4. Inhibition of cholesterol $7 \alpha$-hydroxylase activity by cholestanol and sitosterol in acetone-treated human liver microsomes. The enzyme activity was assayed with $\left[4-{ }^{14} \mathrm{C}\right]-$ cholesterol as described in Methods in the presence of $(A)$ detergent-solubilized unlabeled cholestanol, or (B) sitosterol. Each bar represents the mean \pm SEM of four normal subjects, each assayed in duplicate. The

broken line represents cholesterol $7 \alpha$-hydroxylase activity in acetonetreated liver microsomes from four normal subjects in the absence of exogenous inhibitors $(100 \%=22.1 \pm 1.1 \mathrm{pmol} / \mathrm{nmol} \mathrm{P}-450 / \mathrm{min}) . *$, significantly $<100 \%, P<0.01$.

Enzyme inhibition and kinetics. The effect of cholestanol and sitosterol on the $7 \alpha$-hydroxylation of cholesterol is demonstrated in Figs. 3 and 4 . In these experiments, incubations were carried out with increasing amounts of unlabeled cholestanol or sitosterol added to acetone-treated microsomes. Radioactive cholesterol was the substrate and labeled $7 \alpha$-hydroxycholesterol was the product measured. The results show that cholestanol is a far more potent inhibitor of cholesterol $7 \alpha$-hydroxylation than sitosterol, probably because of its greater affinity for the enzyme as compared with sitosterol (Fig. 2). In the rat, sitosterol (100 $\mu \mathrm{M})$ inhibited cholesterol $7 \alpha$-hydroxylase activity $30 \%$, whereas $100 \mu \mathrm{M}$ cholestanol inhibited it $60 \%$ (Fig. 3). In acetone-treated microsomes from human liver, $100 \mu \mathrm{M}$ sitosterol and $50 \mu \mathrm{M}$ cholestanol inhibited cholesterol $7 \alpha$-hydroxylase activity $\sim 40 \%$ (Fig. 4). For the determination of the type of inhibition, enzyme activities were measured in acetone-treated rat liver microsomes with two different concentrations of cholestanol or sitosterol and increasing concentrations of labeled cholesterol substrate (Figs. 5 and 6). The Lineweaver-Burk double reciprocal plots showed straight lines that intersected at the same point on the ordinates, indicating competitive inhibition of cholesterol $7 \alpha$ hydroxylase by cholestanol and sitosterol.

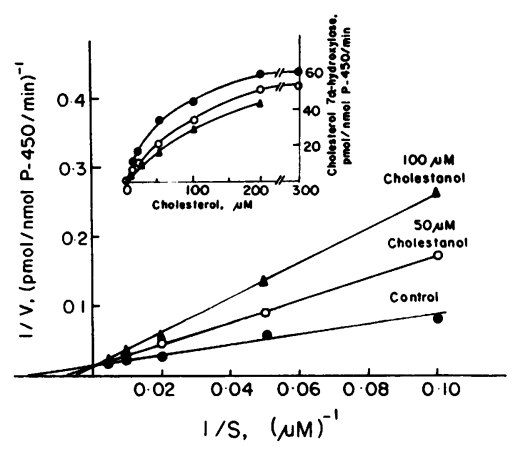

Figure 5. LineweaverBurk plots of cholesterol $7 \alpha$-hydroxylase activity in acetone-treated rat liver microsomes, measured with increasing concentrations of labeled cholesterol in the presence of 0,50 , and $100 \mu \mathrm{M}$ unlabeled cholestanol. S, cholesterol substrate concentration; $\mathrm{V}$, cholesterol $7 \alpha$-hydroxylase activity. Each point represents the average of two to three experiments run in duplicate. 


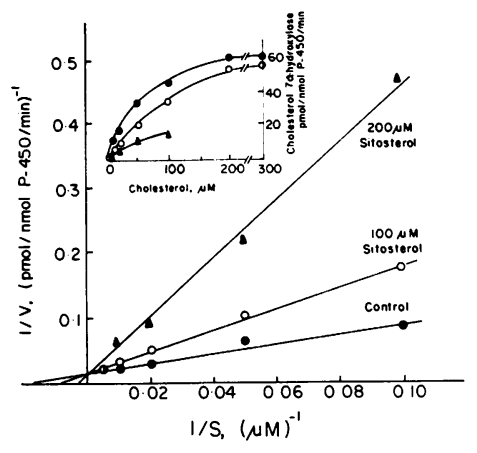

To test the effect of microsomal sterols on cholesterol $7 \alpha$ hydroxylase activity in a clinical situation, the activities of cholesterol $7 \alpha$-hydroxylase were measured in untreated and acetone-treated microsomal preparations obtained from two patients with sitosterolemia with xanthomatosis and compared with those of six control subjects (Table II). Sterol concentrations were determined in both acetone-treated and untreated microsomes. The cholesterol $7 \alpha$-hydroxylase activity observed in untreated microsomes was substantially lower in the two sitosterolemic patients than in control subjects (13.9 and 14.7 compared with the control mean \pm SEM of $20.3 \pm 0.9$ $\mathrm{pmol} / \mathrm{nmol} \mathrm{P}-450 / \mathrm{min}, P<0.01$ ). The lower cholesterol $7 \alpha-$ hydroxylase activity in the sitosterolemic microsomes was associated with significantly higher concentrations of endogenous cholestanol and plant sterols that amounted to $18 \%$ of the microsomal sterol pool. After treatment with acetone to remove endogenous sterols, sitosterolemic microsomal cholesterol $7 \alpha$-hydroxylase activity increased $40 \%$ when assayed in the reconstituted system, which contained optimal amounts of cholesterol. In these experiments, with either untreated or reconstituted sitosterolemic microsomes, only the conversion of cholesterol to $7 \alpha$-hydroxycholesterol was measured. The decrease in cholesterol $7 \alpha$-hydroxylase activity in the untreated microsomes from the patients with sitosterolemia with xanthomatosis thus may reflect competitive inhibition by the coexisting endogenous cholesterol analogues (cholestanol, plant sterols, and their $5 \alpha$-stanols). Ileal bypass surgery in one sitosterolemic subject decreased plasma cholestanol and plant sterols from 29 to $15 \mathrm{mg} / \mathrm{dl}$ and was accompanied by a $30 \%$ increase in cholesterol $7 \alpha$-hydroxylase activity in untreated microsomes (from 13.9 to $17.9 \mathrm{pmol} / \mathrm{nmol} \mathrm{P}-450 / \mathrm{min}$ ).

\section{Discussion}

The results of this investigation emphasize the important effect of the microsomal sterol substrate pool on cholesterol $7 \alpha$-hydroxylase activity. Optimal assay conditions were determined for measuring the $7 \alpha$-hydroxylation of cholestanol and sitosterol in comparison to cholesterol in acetone-treated microsomes from which virtually all endogenous sterols had been removed. The enzyme was assayed at saturation levels of substrate $(200 \mu \mathrm{M})$, with enzyme concentration of $0.2-1.0 \mu \mathrm{M}$ $\mathrm{P}-450$ and incubation time of $10 \mathrm{~min}$ that were in the linear range of enzyme activity (Fig. $1, A-C$ ). The membrane phospholipids lost during acetone treatment of the microsomes were replaced in the incubation mixture with DPLC, the major constituent of liver membrane phospholipids (24). The amount of $\mathrm{Na}$-deoxycholate used to solubilize DLPC was shown previously not to inhibit microsomal cholesterol $7 \alpha$-hydroxylase (2). Individual phospholipids were not identified since these lipids apparently do not act directly on cholesterol $7 \alpha$-hydroxylase but facilitate interaction of the enzyme with NADPH-cytochrome P-450 reductase and can be replaced by an excess of the latter (25). Triton X-100 (0.15\%) was used as a solubilizing agent for the substrates and was found to yield comparable enzyme activities to $0.3 \%$ Triton WR-1339 but higher activities than Cutscum or Tween- 80 used in earlier assays (6). The total sterol concentration that could be used with $0.15 \%$ Triton X-100 did not exceed $300 \mu \mathrm{M}$ (Fig. 6, inset). Over this concentration, high variability of enzyme activity in replicates was observed, possibly due to incomplete solubilization of the sterols. Under the assay conditions used in these experiments, the variation coefficient of cholesterol $7 \alpha$-hydroxylase activity of the acetone-treated microsomes was $<6 \%$.

Table II. Effect of Endogenous Cholesterol Analogues on Hepatic Cholesterol 7 $\alpha$-Hydroxylase Activity in Humans

\begin{tabular}{|c|c|c|c|c|c|}
\hline \multirow[b]{2}{*}{ Subject } & \multirow[b]{2}{*}{ Microsomes } & \multicolumn{3}{|c|}{ Microsomal sterols* } & \multirow{2}{*}{$\begin{array}{c}\text { Cholesterol } \\
7 \alpha \text {-hydroxylase activity }\end{array}$} \\
\hline & & Total & Cholestanol & Plant sterols & \\
\hline & & $n m o l / m g$ protein & & & $\mathrm{pmol} / \mathrm{nmol} P-450 / \mathrm{min}$ \\
\hline \multirow[t]{2}{*}{ Control } & Untreated & 60.1 & 0.2 & ND & $20.3 \pm 0.9$ \\
\hline & Acetone-treated & 0.48 & ND & ND & $22.1 \pm 1.1$ \\
\hline \multirow[t]{2}{*}{ Sitosterolemia } & Untreated & 67.8 & 1.9 & 16.1 & $14.3^{\S}$ \\
\hline & Acetone-treated & 0.54 & ND & ND & 20.0 \\
\hline
\end{tabular}

* The composition of the plant sterols in microsomes from sitosterolemic patients was as follows: sitosterol, $8.6 \%$; campesterol, 5.9\%; $5 \alpha$-sitostanol, $0.9 \%$; and $5 \alpha$-campestanol, $0.7 \%$. N.D. $=$ none detected. ${ }^{\ddagger}$ The mass of $7 \alpha$-hydroxycholesterol formed by the untreated microsomes was determined by the isotope derivative method (17) to avoid underestimation by dilution with the endogenous cholesterol pool. When acetone-treated microsomes were used, the isotope incorporation method was used as described in Methods. The numbers represent means $\pm S E M$ of six control subjects and the averages of two patients with sitosterolemia and xanthomatosis. ${ }^{\S}$ Significantly lower than controls $(P<0.01)$. The concentrations of endogenous cholestanol and sitosterol present in the in vitro assay of the untreated microsomes from sitosterolemic patients were $>5$ and $>25 \mu \mathrm{M}$, respectively, based on the use of 2-3 mg microsomal protein in a total volume of $0.5 \mathrm{ml}$ incubation mixture. 
In the study of substrate specificity, cholestanol was selected as the substrate because it contains the identical isooctyl side chain as cholesterol but does not retain its $\Delta^{5}$-steroid nucleus. The plant sterol, sitosterol, was selected because it differs from cholesterol only by its additional ethyl substituent at C-24 of the side chain. Both compounds are present in abundant amounts in microsomes of patients with sitosterolemia with xanthomatosis (Table II). The affinity of the $7 \alpha$-hydroxylating enzyme toward these substrates was evaluated in acetone-treated microsomes (Fig. 2 B). It was greatest for cholesterol and poorest for sitosterol. Cholestanol, which has the same isooctyl side chain as cholesterol, exhibited almost the same affinity toward the enzyme. The difference in the nuclear structure did not interfere with the enzymatic hydroxylation of cholestanol. These findings are consistent with the results of Bergstrom et al. (26) and Boyd et al. (27), who studied the $7 \alpha$-hydroxylation of several cholesterol analogues and suggested that cholesterol $7 \alpha$-hydroxylase has a specific binding site for the apolar side chain of cholesterol. This binding site may be required for the orientation of the substrate on the enzyme to allow the hydroxylation to occur stereospecifically at the $7 \alpha$-position. When the $7 \alpha$-hydroxylation of sitosterol was carried out with the untreated microsomes, it was barely detectable, as has been observed earlier by Aringer and Eneroth (3) and by Boyd et al. (27), but showed an eightfold increase upon removal of endogenous cholesterol (Fig. 2 B). Similarly, the $7 \alpha$-hydroxylation of cholestanol was lower in untreated relative to acetone-treated microsomes. This suggests that the large microsomal cholesterol pool competes with sitosterol and cholestanol and partially masks their $7 \alpha$-hydroxylation. Only when the microsomal cholesterol pool is removed by acetone treatment is the $7 \alpha$-hydroxylation of sitosterol shown to be significant.

In this study, cholestanol was shown to inhibit cholesterol $7 \alpha$-hydroxylase activity up to $75 \%$, whereas sitosterol inhibited it maximally $40 \%$ (Fig. 3). In earlier studies with the rat, low inhibition of cholesterol $7 \alpha$-hydroxylase by cholestanol (2) and lack of inhibition by sitosterol (3) have been reported and were probably due to the confounding effect of the endogenous microsomal cholesterol pool in the untreated microsomes that were used. The double reciprocal plots demonstrated that both cholestanol and sitosterol were competitive inhibitors of cholesterol (Figs. 5 and 6). The apparent $K_{\mathrm{m}}$ of cholesterol $7 \alpha$-hydroxylase measured in the presence of $50 \mu \mathrm{M}$ cholestanol or $100 \mu \mathrm{M}$ sitosterol was $87 \mu \mathrm{M}$ compared with the $K_{\mathrm{m}}$ of $46 \mu \mathrm{M}$ observed in the absence of any added inhibitor. With $100 \mu \mathrm{M}$ cholestanol, the apparent $K_{\mathrm{m}}$ increased to $117 \mu \mathrm{M}$. Thus, cholestanol is a potent inhibitor of the conversion of cholesterol to its $7 \alpha$-hydroxylated derivative and has similar affinity as cholesterol toward cholesterol $7 \alpha$-hydroxylase. Sitosterol, on the other hand, is a less effective inhibitor, has much less affinity for the enzyme and can be $7 \alpha$-hydroxylated up to $26 \%$ relative to the $7 \alpha$-hydroxylation of cholesterol when competing endogenous cholesterol is removed.

In this study, we have demonstrated for the first time that human liver microsomal cholesterol $7 \alpha$-hydroxylase activity is preserved after the removal of endogenous sterols by acetone treatment. In human liver, as in the rat, $50 \mu \mathrm{M}$ cholestanol or sitosterol inhibited cholesterol $7 \alpha$-hydroxylase activity 35 or $16 \%$, respectively. The importance of this observation concerns cholesterol $7 \alpha$-hydroxylase activity in the rare inherited lipid storage disease, sitosterolemia with xanthomatosis, in which the overabsorption of plant sterols leads to the accumulation of sitosterol and $5 \alpha$-saturated stanols in all tissues, including the liver (5). The reduced cholesterol $7 \alpha$-hydroxylase activity in the patients' untreated microsomes relative to controls was associated with increased amounts of endogenous cholestanol and plant sterols (Table II). Removal of endogenous sterols by acetone treatment of the microsomes resulted in a $40 \%$ increase in cholesterol $7 \alpha$-hydroxylase activity in the sitosterolemic specimens but did not affect the enzyme activity in the control specimens. When cholestanol or sitosterol was added to human acetone-treated microsomes (Fig. 4) at concentrations $(10$ or $50 \mu \mathrm{M})$ that were similar to those present in assays of untreated microsomes from patients with sitosterolemia with xanthomatosis, cholesterol $7 \alpha$-hydroxylase activity was reduced 9 and $16 \%$, respectively. The greater inhibitory effect on enzyme activity of endogenous cholesterol analogues observed in microsomes from patients with sitosterolemia and xanthomatosis (40\%, Table II) may be due to the presence of additional endogenous cholesterol analogues such as campesterol. Preliminary experiments in our laboratory showed that campesterol, the second most abundant plant sterol in the patients' microsomal samples, inhibited cholesterol $7 \alpha$-hydroxylase activity to a similar extent as sitosterol. In addition, the higher inhibitory effect of endogenous cholesterol analogues relative to that observed with exogenous inhibitors may be due to greater availability of endogenous substrate/inhibitors (28).

After ileal bypass surgery, endogenous sterols and $5 \alpha$ stanols decreased $50 \%$ and hepatic cholesterol $7 \alpha$-hydroxylase activity increased $30 \%$. The rise in activity may be due to both a partial removal of competing cholesterol analogues and an induction of enzyme activity by the interruption of the enterohepatic circulation (2). Recently, Miettinen et al. (29) and Ilias et al. (30) reported that gallstones and bile from patients with cholelithiasis contained substantial amounts of cholestanol, plant sterols, and cholesterol precursors. Further, decreased bile acid pools ( 31 ) and low cholesterol $7 \alpha$-hydroxylase activities (32) have been reported in patients with cholelithiasis. It is tempting to speculate that the lower bile acid synthesis in this condition relates to competitive inhibition of cholesterol $7 \alpha$-hydroxylase by the associated abnormal microsomal sterol environment. It is important to emphasize that it is difficult to extrapolate an in vitro enzyme activity, expressed as picomole product formed per nanomole cytochrome P-450 per minute, to a daily bile acid synthetic rate expressed in milligrams bile acids formed per kilogram body weight per day. However, cholesterol $7 \alpha$-hydroxylase activity reflects the rate of bile acid synthesis since increased or decreased enzyme activity, as measured in vitro, correlates with higher or lower bile acid production rates determined in vivo $(2,33)$. The conversion of sitosterol and cholestanol to primary bile acids has been demonstrated in humans (34) and rats $(35,36)$, which indicates that both cholesterol analogues are $7 \alpha$-hydroxylated in vivo.

In summary, this study demonstrates the effect of structurally similar sterols on cholesterol $7 \alpha$-hydroxylase activity in rat and human liver microsomes. Although cholestanol and sitosterol are normally present in only trace amounts in mammalian tissues, increased concentrations in some disease states can substantially reduce bile acid synthesis. This inhibitory effect can be demonstrated by measuring cholesterol $7 \alpha$-hydroxylase activity both in the presence and absence of endoge- 
nous microsomal sterol substrate(s). Thus, analogues of cholesterol may reduce the transformation of cholesterol to bile acids, thereby hindering its removal from the body, and may contribute to premature atherosclerosis in sitosterolemia with xanthomatosis.

\section{Acknowledgments}

The skillful technical assistance of Ms. Eva Paroulek and Ms. Eva Horak is gratefully acknowledged.

This work was supported in part by U. S. Public Health Service grants DK-26756, HL-17818, and DK-18707.

\section{References}

1. Shefer, S., G. Salen, and A. K. Batta. 1986. Methods of assay. In Cholesterol $7 \alpha$-Hydroxylase ( $7 \alpha$-Monooxygenase). R. Fears and J. R. Sabine, editors. CRC Press, Inc., Boca Raton, FL. 43-49.

2. Shefer, S., S. Hauser, and E. H. Mosbach. 1968. $7 \alpha$-Hydroxylation of cholestanol by rat liver microsomes. J. Lipid Res. 9:328-333.

3. Aringer, L., and P. Eneroth. 1973. Studies on the formation of $\mathrm{C}_{7}$-oxygenated cholesterol and $\beta$-sitosterol metabolites in cell-free preparations of rat liver. J. Lipid Res. 14:563-572.

4. Salen, G. 1971. Cholestanol deposition in cerebrotendinous xanthomatosis: a possible mechanism. Ann. Intern. Med. 75:843-851.

5. Salen, G., I. Horak, M. Rothkopf, J. L. Cohen, J. Speck, G. S. Tint, V. Shore, B. Dayal, T. Chen, and S. Shefer. 1985. Lethal atherosclerosis associated with abnormal plasma and tissue sterol composition in sitosterolemia with xanthomatosis. J. Lipid Res. 26:1126-1133.

6. Shefer, S., F. W. Cheng, S. Hauser, A. K. Batta, and G. Salen. 1981. Regulation of bile acid synthesis. Measurement of cholesterol $7 \alpha$-hydroxylase activity in rat liver microsomal preparations in the absence of endogenous cholesterol. J. Lipid Res. 22:532-536.

7. Salen, G., S. Shefer, and V. M. Berginer. 1983. Familial diseases with storage of sterols other than cholesterol: cerebrotendinous xanthomatosis and sitosterolemia with xanthomatosis. In The Metabolic Basis of Inherited Disease. J. B. Stanbury, J. B. Wyngaarden, D. S. Frederickson, J. L. Goldstein, and M. S. Brown, editors. McGraw-Hill Book Co., Inc., New York. 713-730.

8. Dayal, B., G. S. Tint, A. K. Batta, J. Speck, A. K. Khachadurian, S. Shefer, and G. Salen. 1982. Identification of $5 \alpha$-stanols in patients with sitosterolemia with xanthomatosis: stereochemistry of the protonolysis of steroidal organoboranes. Steroids. 40:233-243.

9. Fieser, L. F., J. E. Herz, M. W. Klohs, M. A. Romero, and R. Utne. 1952. Cathylation (carbethoxylation) of steroid alcohols. J. Am. Chem. Soc. 74:3309-3313.

10. Wintersteiner, O., and M. Moore. 1943. Preparation and properties of the 7-epimeric cholestane-diols-3(B),7. J. Am. Chem. Soc. 65:1503-1507.

11. Starka, L. 1961. Reaktion der steroide mit tert-Butylperbenzoat. I. Uber die 7-acyloxylierung $\Delta^{5}$-ungesatigter steroide. Collect. Czech. Chem. Commun. 26:2452-2455.

12. Yasukochi, Y., and B. S. S. Masters. 1976. Some properties of a detergent-solubilized NADPH-cytochrome C (cytochrome P 450) reductase purified by biospecific affinity chromatography. J. Biol. Chem. 251:5337-5344.

13. Koopman, B. J., J. C. van der Molen, B. G. Walthers, A. E. J. de Jager, R. J. Waterreus, and C. H. Gips. 1984. Capillary gas chromatographic determination of cholestanol/cholesterol ratio in biological fluids. Its potential usefulness for the follow-up of some liver diseases and its lack of specificity in diagnosing CTX (cerebrotendinous xanthomatosis). Clin. Chim. Acta. 137:305-315.

14. Lowry, O. H., N. J. Rosebrough, L. A. Farr, and R. J. Randall. 1951. Protein measurement with the Folin phenol reagent. J. Biol. Chem. 193:265-275.
15. Omura, T., and R. Sato. 1964. The carbon monoxide-binding pigment of liver microsomes. J. Biol. Chem. 239:2379-2385.

16. Chen, P. S., Jr., T. Y. Toribara, and H. Warner. 1956. Microdetermination of phosphorus. Anal. Chem. 28:1756-1758.

17. Shefer, S., G. Nicolau, and E. H. Mosbach. 1975. Isotope derivative assay of microsomal cholesterol $7 \alpha$-hydroxylase. J. Lipid Res. 16:92-96.

18. Neter, J., and W. Wasserman. 1974. Applied Linear Statistical Models. Richard D. Irwin, Inc., Homewood, IL. 1-143.

19. Nicolau, G., S. Shefer, G. Salen, and E. H. Mosbach. 1974. Determination of hepatic cholesterol $7 \alpha$-hydroxylase activity in man. J. Lipid Res. 15:146-151.

20. Yokohama, H., I. Ohtsuka, H. Shiojiri, K. Katayama, and S. Ishikawa. 1986. A high performance liquid chromatography method for the assay of cholesterol $7 \alpha$-hydroxylase activity. Anal. Biochem. 157:186-190.

21. Van Cantfort, J., J. Renson, and J. Gielen. 1975. Rat liver cholesterol $7 \alpha$-hydroxylase. Eur. J. Biochem. 55:23-31.

22. Kwok, C. T., W. Burnett, and I. R. Hardie. 1981. Regulation of rat liver microsomal cholesterol $7 \alpha$-hydroxylase: presence of a cytosolic activator. J. Lipid Res. 22:570-579.

23. Ozasa, K., and J. S. Boyd. 1981. Cholesterol $7 \alpha$-hydroxylase of rat liver. Studies on solubilization, resolution and reconstitution of the enzyme complex. Eur. J. Biochem. 119:263-272.

24. Waskell, L., D. Koblin, and E. Canova-David. 1982. The lipid composition of human liver microsomes. Lipids. 17:317-320.

25. Miwsa, G. T., and A. Y. H. Lu. 1984. The association of cytochrome P-450 and NADPH-cytochrome P-450 reductase in phospholipid membranes. Arch. Biochem. Biophys. 234:161-166.

26. Bergstrom, S., S. Linstredt, B. Samuelsson, E. J. Corey, and G. S. Gregoriou. 1958. The stereochemistry of $7 \alpha$-hydroxylation in the biosynthesis of cholic acid from cholesterol. J. Am. Chem. Soc. 80:2337-2338.

27. Boyd, G. S., M. J. G. Brown, N. G. Hattersley, and K. E. Suckling. 1974. Studies on the specificity of the rat liver microsomal cholesterol $7 \alpha$-hydroxylase. Biochim. Biophys. Acta. 337:132-135.

28. Bjorkhem, I., and H. Danielsson. 1975. $7 \alpha$-Hydroxylation of exogenous and endogenous cholesterol in rat liver microsomes. Eur. $J$. Biochem. 53:63-70.

29. Miettinen, T. A., Y. A. Kesaniemi, H. Jarvinen, and J. Hastbacka. 1986. Cholesterol precursor sterols, plant sterols, and cholestanol in human bile and gallstones. Gastroenterology. 90:858-864.

30. Ilias, A. M., W. E. Connor, H. T. Cory, D. S. Lin, G. D. Daves, Jr., and W. W. Krippaehne. 1980. Sterols of human gallstones: the recent identification of eight different digitonin precipitable sterols. Gastroenterology. 79:539-544.

31. Almond, H. R., Z. R. Vlahcevic, C. C. Bell, Jr., D. H. Gregory, and L. Swell. 1973. Bile acid pools, kinetics and biliary lipid composition before and after cholecystectomy. N. Engl. J. Med. 289:12131216.

32. Salen, G., G. Nicolau, S. Shefer, and E. H. Mosbach. 1975. Hepatic cholesterol metabolism in patients with gallstones. Gastroenterology. 69:676-684.

33. Shefer, S., S. Hauser, I. Bekersky, and E. H. Mosbach. 1969. Feedback regulation of bile acid biosynthesis in the rat. J. Lipid Res. 10:646-655.

34. Salen, G., E. H. Ahrens, Jr., and S. M. Grundy. 1970. Metabolism of $\beta$-sitosterol in man. J. Clin. Invest. 49:952-967.

35. Shefer, S., S. Hauser, G. Salen, F. G. Zaki, J. Bullock, E. Salgado, and J. Shevitz. 1984. Comparative effects of cholestanol and cholesterol on hepatic sterol and bile acid metabolism in the rat. $J$. Clin. Invest. 74:1773-1781.

36. Ziller, S. A., Jr., E. A. Doisy, and W. H. Elliot. 1968. Bile acids XXV. allochenodeoxycholic acid, a metabolite of $5 \alpha$-cholestan-3 3 -ol in the hyperthyroid rat liver microsomes. J. Lipid Res. 9:328-333. 